\title{
EXECUÇÃO DA ESTRATÉGIA EMPRESARIAL
}

0 mundo está repleto de bons planos que falham devido a uma execução deficiente. Apesar disso, o estudo sistemático da estratégia empresarial, que teve origem na década de 1960, tem dado pouca atenção à execução das estratégias, concentrando-se na análise, concepção, planejamento e posicionamento da empresa no seu ramo de atividade. São abundantes os livros publicados sobre a formulação de estratégias empresariais, mas poucos tratam da sua execução. 0 resultado dessa negligência foi, frequentemente, a descoberta de sérias dificuldades na implementação da estratégia, o que levou ao seu abandono ou ao insucesso em atingir os resultados esperados. Na última década, porém, a execução da estratégia ganhou status e passou a ser considerada importante na gestão. Abaixo, são comentados livros sobre o tema, selecionados por Fábio L. Mariotto, professor titular da FGV-EAESP.

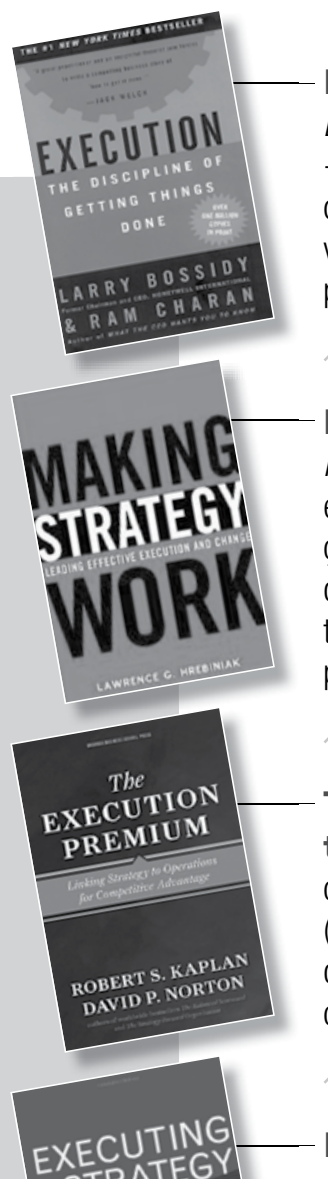

EXECUTION: The discipline of getting things done. Larry Bossidy, Ron Charan e Charles Burck. New York: Crown Business, 2002. 320 p. Este foi o primeiro livro sobre execução de estratégia a tornar-se um best-seller. Dirigido a executivos, deve interessar também a consultores, professores de negócios e todos os que desejam que seus planos se realizem. Nada do que o livro diz é realmente uma novidade, mas ele tem a virtude de organizar suas observações e recomendações de modo a ressaltar os passos e cuidados necessários para transformar projetos em realidade.

MAKING STRATEGY WORK: Leading effective execution and change. Lawrence $G$. Hrebiniak. Upper Saddle River: Pearson Education, 2005. 408 p. Este livro contrasta com o anterior por ter um embasamento predominantemente acadêmico. Enquanto Execution é essencialmente uma lista de recomendações, Making strategy work dá uma abordagem integrada à execução estratégica, apresentando e detalhando decisões-chave na execução de planos. A principal contribuição que este livro traz à literatura de gestão estratégica é integrar, em uma clara estrutura conceitual, ideias provindas de variadas fontes e que, até agora, permaneciam pulverizadas.

THE EXECUTION PREMIUM: Linking strategy to operations for competitive advantage. Robert S. Kaplan e David P. Norton. Boston: Harvard Business School, 2008. 320 p. Esta é a mais recente contribuição de Kaplan e Norton para a já famosa série de textos em que propõem o uso do "boletim equilibrado" (balanced scorecard) e de mapas estratégicos para controlar a execução de planos. Esse último texto é um verdadeiro compêndio das abordagens mais recentes na formulação e execução de estratégias, por meio de uma cobertura abrangente desses tópicos. A argumentação é muito analítica e financeira e pouco comportamental.

EXECUTING YOUR STRATEGY: How to break it down and get it done. Mark Morgan, Raymond E. Levitt e William A. Malek. Boston: Harvard Business School, 2007. 304 p. Os autores estão ligados ao programa Stanford Advanced Project Management (SAPM), que mescla teoria acadêmica com processos da vida real, visando capacitar os indivíduos e as organizações a executar programas e carteiras de projetos. A ênfase do livro está na aplicação de conceitos trazidos da gestão de projetos para conseguir uma execução bem-sucedida da estratégia, o que representa um avanço na teoria da estratégia empresarial.

THE 4 DISCIPLINES OF EXECUTION: Achieving your wildly important goals. Chris McChesney, Sean Covey e Jim Huling. New York: The Free Press, 2012. 352 p. Este é o mais recente livro de execução de estratégia entre os comentados aqui. Sean Covey é o autor do famigerado livro Os sete hábitos das pessoas muito eficazes, o que já dá uma ideia do tipo de leitura, que alguns considerariam de autoajuda. 0 livro foi lançado com muita fanfarra e depoimentos favoráveis de famosos executivos e acadêmicos, mas ainda não se tornou um best-seller. 